\title{
A retrospective study on the outcomes of cataract surgery in an Eastern Regional Health Authority Hospital of Trinidad and Tobago
}

Ebiakpo-aboere Sonron, Vrijesh Tripathi, Petra Bridgemohan, Subash Sharma

Background: Worldwide, cataract is a major cause of blindness. The paper aims to evaluate factors associated with borderline and poor outcomes of cataract surgery at an Eastern Regional Health Authority (ERHA) hospital in Trinidad and Tobago. Materials and methods: A hospital-based, retrospective study was done on 401 patients who had undergone cataract surgery (unilateral and bilateral) at an ERHA Hospital between March 2009 and September 2014. Data was collected on variables concerning demographic, medical history, surgical history, ocular findings and visual acuity (VA). The outcome variable of interest was Snellen's post-operative (presenting) VA which was transformed into a dichotomous variable with borderline and poor outcomes as one and good outcomes as the other. Data were analysed using univariate and multivariate logistic regression analyses. Results: Good outcome (presenting VA 6/18 or better) was seen in 350 (67\%) eyes. The fitted model consisted of ocular co-morbidity $(\mathrm{OR}=2.133 ; 95 \% \mathrm{Cl} 1.346$ to 3.380 ), hypertension $(\mathrm{OR}=0.520 ; 95 \% \mathrm{Cl} 0.381$ to 0.928$)$, surgical procedure $(\mathrm{OR}=1.56$; $95 \% \mathrm{Cl} 1.004$ to 2.425$)$, good preoperative $\mathrm{VA}(\mathrm{OR}=0.388,95 \% \mathrm{Cl} 0.211$ to 0.714 ), borderline preoperative $\mathrm{VA}(\mathrm{OR}=0.485 ; 95 \% \mathrm{Cl}=0.278$ to 0.843$)$ and year of first visit to clinic ( $O R=2.243 ; 95 \% \mathrm{Cl} 1.215$ to 4.141$)$. Conclusion: There is a need for communitybased outreach to increase awareness of eye health and diseases. It is recommended that the general population is encouraged to take responsibility for personal management. The facilities at the Hospital should also be enhanced. 
1 Title: A retrospective study on the outcomes of cataract surgery in an Eastern Regional Health

2 Authority Hospital of Trinidad and Tobago.

3

4

\section{Ebiakpo-aboere Sonron ${ }^{1}$, Vrijesh Tripathi ${ }^{1 *}$, Petra Bridgemohan ${ }^{2}$ and Subash Sharma ${ }^{3}$}

${ }^{1}$ Department of Mathematics \& Statistics, The University of the West Indies, Faculty of Science and Technology, St. Augustine, Trinidad and Tobago.

${ }^{2}$ Ophthalmology Department, Sangre Grande Hospital, Eastern Regional Health Authority, Trinidad and Tobago.

${ }^{3}$ School of Optometry and Visual Sciences, the University of the West Indies, St. Augustine, Trinidad and Tobago.

*For correspondence:

Name: Vrijesh Tripathi, Ph D

Department of Mathematics \& Statistics,

St. Augustine, Trinidad and Tobago.

Faculty of Science and Technology,

The University of the West Indies, St. Augustine, Trinidad and Tobago.

Email: vrijesh.tripathi@sta.uwi.edu 


\section{INTRODUCTION}

Cataract is defined as the opacification of the eye's natural lens and can develop in a few months or take several years (Baltussen et al. 2004; Fattore \& Torbica 2008). Global data on visual impairment attributes $51 \%$ of blindness in the world to cataract affecting approximately 18 million people worldwide (International Agency for the Prevention of Blindness ; Pascolini \& Mariotti 2011; Lindfield et al. 2012). In the Caribbean, non-operated cataract is the most prevalent cause of blindness (PAHO 2002). According to the Barbados Eye Studies, visual impairment occurs in $12 \%$ of the people $40-84$ years old and $3 \%$ suffer from severe visual impairment. Furthermore, age-related cataract alongside open-angle glaucoma (OAG) accounts for $73.2 \%$ of blindness, with two-thirds of low vision (visual acuity from $<6 / 18$ to $<6 / 120$ ) being attributed to cataract (Leske et al. 2010). Approximately $70 \%$ of eye surgeries in Trinidad and Tobago are for the removal of cataracts with 2500 cataract extractions and presentation of 3000 new cases annually at the public hospitals (Choy 2012). The risk factors for cataract development include gender, diabetes mellitus, exposure to excessive sunlight, life style, eye injury and use of steroids (The Royal College of Ophthalmologists 2010). Data from twin genetic studies estimate a heritability between $48 \%$ - 59\% of age-related cataract (Hammond et al. 2000; Hammond et al. 2001). managed by the Eastern Regional Health Authority (ERHA) of Trinidad and Tobago. The ERHA provides healthcare for the catchment population of approximately 120,000 from Matelot in the north to Guayaguayere, Rio Claro and Brothers Road in the South to Valencia in the east.

Cataract surgical services offered by the Ophthalmology Clinic began in March 2009 and are done as outpatient surgeries. The clinic is a referral centre and cataract patients are routinely 
given an appointment date that is 6 months from the time they come in with their referral. Those who suffer from complications such as glaucoma and diabetic retinopathy (DR) are given priority. This results in some patients being on the waiting list for at least 2 years.

The outcomes of cataract surgery can be measured using an objective clinical indicator such as visual acuity (VA) and/or subjective indicators such as quality of life (QOL) and visual functioning (VF) instruments. This paper uses VA to measure the outcomes of cataract surgery at SG Hospital. In its guidelines, the World Health Organisation (WHO) recommends that all patients undergoing cataract surgery should have VA measured in each eye preoperatively, and anytime between discharge and 12 weeks (World Health Organisation 1998). The objective of this paper is to evaluate the visual outcomes at the SG Hospital and to investigate factors associated with borderline and poor outcomes. These indentified factors can possibly lead to the establishment of a framework for improving the outcomes of cataract surgery.

\section{MATERIALS AND METHODS}

This was a hospital-based, retrospective study on patients who had undergone cataract surgery, unilateral or bilateral, at the Sangre Grande Hospital of the ERHA from March 2009 to September 2014. The main types of cataract surgery done at SG Hospital are phacoemulsification (Phaco) and extracapsular cataract extraction (ECCE) which are both conducted with intraocular lens (IOL) insertion. There were a total of 1100 cataract surgeries that had taken place at SG Hospital during this time period. Patients were selected randomly from the database maintained by the Medical Records Unit and their medical files were reviewed if physically available at the time of the study. This led to a selection of 277 patients with unilateral and 124 patients with bilateral cataract surgery. Around $1 \%$ of the surgeries performed were Small Incision Cataract surgery (SICS) and these cases were excluded from univariate and 
94 multivariate analyses because of their low number. To avoid duplication of patient's information

95 in cases of bilateral cataract surgery, a random number table was used to select which eye would

96 be included in the regression analysis. This led to the selection of 401 patients aged 18-100 as the

97 sample for the study.

98 Explanatory Variables

99 The following variables were recorded from their files: demographic variables such as sex, date

100 of birth, age, marital status, occupation, residence; other variables such as year of first visit to the

101 clinic, referral source, and time between visit to clinic and cataract surgery; ocular findings such

102 as first measurement of VA, post-operative (presenting) VA and intraocular pressure (IOP);

103 ocular co-morbidities including glaucoma, DR and age-related macular degeneration (ARMD);

104 presence of co-incident diseases such as diabetes mellitus, hypertension, cardiovascular disease

105 and high cholesterol; and, variables on surgical history such as surgical procedure used, and

106 previous surgeries, if any.

\section{Statistical Technique}

108 The outcome variable of interest was Snellen's post-operative VA measured at the follow up

109 starting from at least 3 months after surgery. This variable was transformed into a dichotomous

110 variable (Good and Poor) based on the measurements of post-operative VA with borderline and

111 poor outcomes grouped as poor. Univariate logistic regression analysis was conducted to explore

112 the association of the co-variates and the dependent variable. The variables that were moderately

113 significant $(<0.10)$ were then included in forward step-wise multivariate logistic regression. MS

114 Excel, R and IBM SPSS 20.0 statistical packages were used for data management and analyses. 


\section{Ethical approval}

118 The University of the West Indies (UWI) St. Augustine Campus Ethics Committee provided the

119 written approval by letter dated 22 January, 2015 and the Research Ethics Committee of the

120 ERHA provided written ethical approval through letter reference PHO:04/15 dated 25 February

1212015.

\section{RESULTS}

123 Comparison of visual acuity pre and post cataract surgery for data on 525 eyes of 401 patients is 124 graphically presented in Figure 1. Upon first visit to the clinic, preoperative VA showed that 114 125 eyes (22\%) had good VA, 140 eyes (27\%) had borderline VA and 271 eyes $(51 \%)$ had poor VA. 126 Post-operative cataract VA resulted in 350 eyes (67\%) having good VA, 110 eyes (21\%)

127 borderline VA and 65 eyes (12\%) poor VA. This shows that visual acuity improved in 326 eyes $128(62 \%)$, but worsened in 33 eyes (6\%) with no change in 166 eyes $(32 \%)$.

\section{Socio-Demographic Characteristics}

130 The number, frequency and univariate analyses of socio-demographic characteristics of the

131 sample population are given in Table 1. The sample of 401 adults consisted of 200 (49.9\%) men 132 and 201 (50.1\%) women, who had undergone cataract surgery in one (277 subjects) or both eyes 133 (124 subjects). The age at surgery ranged from 23 to 98 years (mean 68.1 \pm 12.1 years). The age 134 at surgery was calculated from having recorded the date of birth and date of surgery for all 135 subjects. Most patients were within the 51-80 age group (76.8\%). 164 (40.9\%) patients were 136 retired. The patients mainly resided in areas that are administered by ERHA with $246(61.3 \%)$

137 patients living in areas including Sangre Grande, Manzanilla and Toco. Referral sources came 138 largely from health centres within the ERHA (34.4\%) and optical centres such as Ferreira Ltd 139 and Dalton Brown \& Long (31.1\%). The odds of having a poor outcome were increased by being 
140 male ( $\mathrm{OR}=1.37,95 \%$ CI 0.91 to 2.08$)$; retired ( $\mathrm{OR}=1.41,95 \% \mathrm{CI} 0.85$ to 2.34$)$, unemployed or

141 on disability allowance ( $\mathrm{OR}=2.58,95 \% \mathrm{CI} 0.87$ to 7.67$)$. However, only the variable year of first

142 visit to clinic ( $\mathrm{OR}=1.85,95 \% \mathrm{CI} 1.07$ to 3.20$)$ was statistically significant at $\mathrm{p}<0.05$ level.

\section{Medical and Surgical History}

144 An examination of medical history shows that diabetes mellitus was present in $41 \%(n=163)$,

145 while hypertension was present in $45 \%(\mathrm{n}=182)$ of the patients. There were more women than

146 men who had diabetes mellitus and hypertension. Patients were also suffering from

147 cardiovascular disease (9\%) and high cholesterol (11\%). Ocular co-morbidity was present in

$14832 \%(\mathrm{n}=128)$ of the patients. Distribution and the results of univariate analyses of each variable

149 are presented in Table 2.

150 Univariate logistic regression found the following six clinical variables statistically significant

151 ( $\mathrm{p}<0.05)$ : good pre-operative VA $(\mathrm{OR}=0.42,95 \% \mathrm{CI} 0.24$ to 0.74$)$, borderline pre-operative VA

$152(\mathrm{OR}=0.56,95 \% \mathrm{CI} 0.34$ to 0.92$)$, ocular co-morbidity ( $\mathrm{OR}=2.14,95 \%$ CI 1.39 to 3.31$)$,

153 hypertension ( $\mathrm{OR}=0.65,95 \% \mathrm{CI} 0.43$ to 0.99$)$, intraocular pressure ( $\mathrm{OR}=2.30,95 \% \mathrm{CI} 1.27$ to

154 4.19), surgical procedure ( $\mathrm{OR}=1.71,95 \% \mathrm{CI} 1.13$ to 2.60$)$ and other eye surgeries excluding

155 cataract ( $\mathrm{OR}=2.67,95 \% \mathrm{CI} 1.28$ to 5.55$)$. The odds of having poor outcome increased with

156 diabetes mellitus ( $\mathrm{OR}=1.43,95 \% \mathrm{CI} 0.94$ to 2.18$)$; high cholesterol ( $\mathrm{OR}=1.40,95 \% \mathrm{CI} 0.75$ to

157 2.61); and having cataract surgery on the left eye ( $\mathrm{OR}=1.11,95 \% \mathrm{CI} 0.74$ to 1.68$)$. However,

158 these were statistically non-significant in our analyses. Surgical technique used was statistcally

159 significant with Phacoemulsification being better than ECCE ( $\mathrm{OR}=1.71,95 \%$ CI 1.13 to 2.60$)$.

160 Multivariate Analyses

161 Multivariate logistic regression showed that other eye surgeries and intraocular pressure did not 162 add significantly to the model. Table 3 shows the variables of the fitted model with their p- 
163 values, odds ratios and $95 \%$ confidence intervals. The fitted model shows that there is an inverse

164 relationship of poor outcomes with hypertension, good and borderline preoperative VA. The 165 odds of having a poor outcome for those with hypertension was $40 \%$ less $(\mathrm{OR}=0.60,95 \% \mathrm{CI}$ 1660.38 to 0.94$)$ than those with no hypertension. The odds of having a poor outcome were reduced 167 by $61 \%$ in those with good preoperative VA (OR=0.39, 95\% CI 0.21 to 0.72$)$ and by $51 \%$ in 168 those with borderline preoperative VA $(\mathrm{OR}=0.49,95 \% \mathrm{CI}=0.28$ to 0.86$)$ when compared to 169 those measured with poor preoperative VA. On the other hand, there is a positive relationship of 170 poor outcomes with ocular co-morbidity, surgical procedure and the year the patient first visited 171 the clinic. Those with an ocular co-morbidity have two-fold increased odds of a poor outcome 172 compared with those with no ocular co-morbidity present (OR=2.13, 95\% CI 1.36 to 3.42 ); year 173 of first visit to the clinic prior to 2009 resulted in twice the odds of a poor outcome compared 174 with those who first visited from 2009 till 2014 (OR=2.24, 95\% CI 1.20 to 4.10); and, the odds 175 of a poor outcome were increased by $56 \%$ for those patients whose surgical procedure was $176 \operatorname{ECCE}(\mathrm{OR}=1.56,95 \% \mathrm{CI} 1.01$ to 2.45$)$.

\section{DISCUSSION}

178 The WHO recommends that a clinical audit record be maintained for all cases of cataract surgery. It mandates that with available correction, acceptable visual outcomes post cataract

180 surgery are good outcome $(6 / 18$ or better) in $>80 \%$ of cases, borderline outcome $(<6 / 18$ to $6 / 60)$ 181 in $<15 \%$, and poor outcome $(<6 / 60)$ in $<5 \%$ of cases (Pararajasegaram 2002). Our data set did 182 not meet these criterias with the figures falling short in each of the categories. The results from 183 population-based surveys elsewhere have shown that $40 \%$ or greater of postoperative eyes have a 184 presenting VA of worse than 6/18 (Dandona et al. 1999; He et al. 1999; Murthy et al. 2001). In 185 this study, the corresponding percentage was just under $34 \%$ which is still significantly high 
186

187

188

189

190

191

192

193

194

195

196

197

198

199

200

201

202

203

204

205

206

207

208

when compared to the benchmark of less than $20 \%$ recommended by WHO (World Health Organisation 1998). It is important that both awareness and facilities are upgraded for the required population.

This study identifies factors that are associated with borderline and poor outcomes of cataract surgery performed at SG Hospital in Trinidad and Tobago. While there is little availability of literature concerning studies done locally or in the Caribbean region, the results of this study are comparable with that of previous international studies (Desai et al. 1999; Norregaard et al. 1998). Some studies (Gupta et al. 2013; Norregaard et al. 1998) use the best corrected visual outcome (BCVA) when assessing visual outcomes but this study used post-operative (presenting) VA since BCVA was not available for all patients. This does not nullify the results of the study as "it is the presenting vision that represents the actual circumstances under which people function in day-to-day activities" (Leon 2000).

Demographic factors such as age, sex and place of residence are not significant factors in this study. Age has been identified as significantly associated with poorer visual outcomes (Norregaard et al. 1998), with patients aged 90 years and over having four times the risk of poor visual outcomes when compared to those aged 50 to 59 years (Desai et al. 1999). There are equal number of males and females in our sample for this study and males have higher odds of poor outcomes when compared to females. However, results from a Pakistan survey and a study from Rajasthan in India show that females are associated with poor outcomes (Bourne et al. 2007; Murthy et al. 2001). Place of residence has limited effect on visual outcomes. Some studies report poor outcomes among rural patients (Dandona et al. 1999), while others ascribe no significant association (Nirmalan et al. 2002). Comparison of places of residences (rural to urban) was beyond the scope of this study as it was hospital-based. For this study, those who did 
not reside in ERHA regions had increased odds of poor outcomes. It is notable that most patients appeared to wait until vision was very poor before visiting the clinic. One plausible reason could be that due to the slow, progressive decline in vision that characterizes the development of cataracts, patients are not aware earlier of the decrease in visual function (Bellan et al. 2008). There is no supporting literature to explain why the odds of a poor outcome increased if the patient first visited the clinic prior to 2009. The only plausible explanation is that those who first visited the clinic prior to the opening of the Ophthalmology Clinic in 2009 are more likely to have had a longer waiting period for cataract surgery. This longer waiting period could possibly have led to higher risks for development of further complications, worsening of symptoms or poor prognosis and outcome following surgery (Hadjistavropoulos et al. 1998; Mojon-Azzi \& Mojon 2007).

The presence of an ocular co-morbidity increases the likelihood of a poor outcome by at least two-fold. This is consistent with the results of previous studies (Desai et al. 1999; Kshitiz et al. 2012; Norregaard et al. 1998) and is seen as a frequent reason for poor self-assessed outcomes of cataract extraction (Lundström et al. 1999; Rönbeck et al. 2011). However, there is no consensus on a proven association between cataract surgery and ocular diseases such as glaucoma (BernthPetersen \& Bach 1983; Harding et al. 1989; Heltzer 2004; Kung et al. 2015), DR (World Health Organisation 2006); Philip Hooper et al. 2012; Hong et al. 2009) and ARMD (Bellan et al. 2008;

Chang et al. 2011; Velez \& Weiter 2002).

Despite the association between ocular co-morbidity and cataract surgery, Lundström et al. (2012) state that it is not a contraindication for cataract surgery. Analyses of systemic comorbidities such as diabetes mellitus, hypertension, cardiovascular disease and high cholesterol revealed that only hypertension is significantly associated with poor visual outcomes. Several 
232 studies identify diabetes mellitus as a risk factor for cataract (Harding et al. 1993; Leske et al.

233 2010). Although diabetes mellitus is not significantly associated with poor outcomes in this

234 study, univariate analyses showed evidence that the odds of poor outcome are increased on

235 having diabetes mellitus. Cardiovascular disease is shown not to be significantly associated with

236 poor outcomes in this study. This is supported by Tan et al. (2008) though other studies support

237 the association of the cardiovascular disease and cataract (Goodrich et al. 1999). Hypertension

238 was inversely related to poor visual outcomes as higher levels reduced the risk of poor visual

239 outcomes when compared to those with no hypertension. There is little literature to explain what

240 leads hypertension to be associated with cataract but Lee et al. (1997) in their study imply that

241 hypertension gives rise to conformational changes in the lens capsule.

242 Phacoemulsification, a procedure developed by Charles D. Kelman (Goldstein 2004), is the

243 preferred surgical procedure while ECCE is performed depending on the condition of the

244 anterior chamber, iris, and lens (Lundström et al. 2012). Phacoemulsification requires a smaller

245 incision and is suture-less which can lead to significant reduction in surgically-induced

246 astigmatism (Kshitiz et al. 2012). In this study, the odds of a poor outcome are increased when

247 the surgical procedure was ECCE which is consistent with previous studies (Desai et al. 1999;

248 Minassian et al. 2001).

249 The study shows that the odds of a poor outcome increase from borderline to poor preoperative

250 VA. This is consistent with the International Cataract Surgery Outcomes Study, where poor

251 preoperative VA is highlighted as one of the predictors of a poor visual outcome (Norregaard 252 2007).

253 There are several limitations in this study. Firstly, this is a retrospective hospital-based study.

254 Secondly, BCVA measurements were not recorded in the data readily available in the medical 
records. Despite these limitations, it is believed that this study adequately identifies factors that are associated with borderline and poor visual outcomes of cataract surgery.

\section{CONCLUSION}

This study identifies the factors that significantly affect visual outcomes such as surgical procedure, preoperative VA, hypertension and ocular co-morbidities. It is recommended that the phacoemulsification technique be increasingly utilized due to evidence for better cataract surgery outcomes when compared to ECCE. There is also a need for community-based outreach to increase awareness of the importance of eye health. Other recommendations include implementing the use of a quality of life (QOL) instrument to assess outcomes of cataract surgery alongside the clinical indicator of visual acuity to ensure that the medical records of patients are complete and thorough as much as possible.

\section{ACKNOWLEDGEMENTS}

The authors would like to thank the staff of the Medical Records Unit of the Sangre Grande Hospital, for their help in providing information from the database and locating medical records used for this study.

\section{REFERENCES}

Baltussen R, Sylla M, and Mariotti SP. 2004. Cost-effectiveness analysis of cataract surgery: a global and regional analysis. Bulletin of the World Health Organization 82:338-345.

Bellan L, Iqbal Ike K. Ahmed, Brent MacInnis, Colin Mann, Françoise Noël, and Sanmugasunderam S. 2008. Canadian Ophthalmological Society evidence-based clinical practice guidelines for cataract surgery in the adult eye. Canadian Journal of Ophthalmology / Journal Canadien d'Ophtalmologie 43, Supplement 1:S7-S33.

Bernth-Petersen P, and Bach E. 1983. Epidemiologic aspects of cataract surgery. III: Frequencies of diabetes and glaucoma in a cataract population. Acta Ophthalmol 61:406-416.

Bourne R, Dineen B, Jadoon Z, Lee PS, Khan A, Johnson GJ, Foster A, and Khan D. 2007. Outcomes of cataract surgery in Pakistan: results from The Pakistan National Blindness and Visual Impairment Survey. The British Journal of Ophthalmology 91:420-426.

Chang DF, Henderson BA, Lee RH, Nichamin LD, Olson RJ, Packer M, Varma R, and American Academy of Opthalmology Cataract and Anterior Segment Panel. 2011. Cataract in the Adult Eye. Preferred Practice Pattern Guidelines. San Francisco, CA: American Academy of Ophthalmology. 
Chernick MR, and LaBudde RA. 2011. An introduction to bootstrap methods with applications to R. New Jersey: John Wiley \& Sons, Inc.

Choy D. 2012. "Khan: Survey on blindness, visual impairment coming". Newsday, July 13. Accessed July 24, 2015. http://newsday.co.tt/news/0,163214.html

Dandona L, Dandona R, Naduvilath TJ, McCarty CA, Mandal P, Srinivas M, Nanda A, and Rao GN. 1999. Population-based assessment of the outcome of cataract surgery in an urban population in southern India. American Journal of Ophthalmology 127:650-658.

Desai P, Minassian DC, and Reidy A. 1999. National cataract surgery survey 1997-8: a report of the results of the clinical outcomes. British Journal of Ophthalmology 83:1336-1340.

Fattore G, and Torbica A. 2008. Cost and reimbursement of cataract surgery in Europe: a cross-country comparison. Health Economics 17:S71-S82.

Goldstein JL. 2004. How a jolt and a bolt in a dentist's chair revolutionized cataract surgery. Nat Med 10:1032-1033.

Goodrich ME, Cumming RG, Mitchell P, Koutts J, and Burnett L. 1999. Plasma fibrinogen and other cardiovascular disease risk factors and cataract. Ophthalmic Epidemiol 6:279-290.

Gupta P, Zheng Y, Ting TW, Lamoureux EL, Cheng C-Y, and Wong T-Y. 2013. Prevalence of Cataract Surgery and Visual Outcomes in Indian Immigrants in Singapore: The Singapore Indian Eye Study. PLOS ONE 8:e75584.

Hadjistavropoulos HD, Snider B, and Bartlett G. 1998. Measuring the quality of performance in the management of waiting lists: using cataract surgery as an example. Jt Comm J Qual Improv 24:407-422.

Hammond CJ, Duncan DD, Snieder H, de Lange M, West SK, Spector TD, and Gilbert CE. 2001. The Heritability of Age-Related Cortical Cataract: The Twin Eye Study. Investigative Ophthalmology \& Visual Science 42:601-605.

Hammond CJ, Snieder H, Spector TD, and Gilbert CE. 2000. Genetic and Environmental Factors in AgeRelated Nuclear Cataracts in Monozygotic and Dizygotic Twins. New England Journal of Medicine 342:1786-1790.

Harding JJ, Egerton M, van Heyningen R, and Harding RS. 1993. Diabetes, glaucoma, sex, and cataract: analysis of combined data from two case control studies. The British Journal of Ophthalmology $77: 2-6$.

Harding JJ, Harding RS, and Egerton M. 1989. Risk factors for cataract in Oxfordshire: diabetes, peripheral neuropathy, myopia, glaucoma and diarrhoea. Acta Ophthalmol 67:510-517.

He M, Xu J, Li S, Wu K, Munoz SR, and Ellwein LB. 1999. Visual acuity and quality of life in patients with cataract in Doumen County, China. Ophthalmology 106:1609-1615.

Heltzer JM. 2004. Coexisting glaucoma and cataract. Ophthalmology 111:408-409.

Hong T, Mitchell P, de Loryn T, Rochtchina E, Cugati S, and Wang JJ. 2009. Development and Progression of Diabetic Retinopathy 12 Months after Phacoemulsification Cataract Surgery. Ophthalmology 116:1510-1514.

Hosmer Jr DW, Lemeshow S, and Sturdivant RX. 2013. Applied Logistic Regression. New Jersey: John Wiley \& Sons, Inc.

International Agency for the Prevention of Blindness. What is avoidable blindness - Cataract. Available at http://www.iapb.org/vision-2020/what-is-avoidable-blindness/cataract (accessed May 29 2015).

Kshitiz K, Gupta V, and Dhaliwal U. 2012. Causes of sub-optimal cataract surgical outcomes in patients presenting to a teaching hospital. Nepalese Journal of Ophthalmology 4:73-79.

Kung JS, Choi DY, Cheema AS, and Singh K. 2015. Cataract Surgery in the Glaucoma Patient. Middle East African Journal of Ophthalmology 22:10-17. 
Lee SM, Lin SY, Li MJ, and Liang RC. 1997. Possible mechanism of exacerbating cataract formation in cataractous human lens capsules induced by systemic hypertension or glaucoma. Ophthalmic Res 29:83-90.

Leon B. 2000. Cataract surgery outcomes: a priority agenda item. Community Eye Health 13:33-34.

Leske MC, Wu S-Y, Nemesure B, Hennis A, and Barbados Eye Studies Group. 2010. Causes of visual loss and their risk factors: an incidence summary from the Barbados Eye Studies. Revista Panamericana de Salud Pública 27:259-267.

Lindfield R, Vishwanath K, Ngounou F, and Khanna RC. 2012. The challenges in improving outcome of cataract surgery in low and middle income countries. Indian Journal of Ophthalmology 60:464469.

Lundström M, Barry P, Henry Y, Rosen P, and Stenevi U. 2012. Evidence-based guidelines for cataract surgery: Guidelines based on data in the European Registry of Quality Outcomes for Cataract and Refractive Surgery database. Journal of Cataract \& Refractive Surgery 38:1086-1093.

Lundström M, Stenevi U, and Thorburn W. 1999. Outcome of cataract surgery considering the preoperative situation: a study of possible predictors of the functional outcome. British Journal of Ophthalmology 83:1272-1276.

Minassian D, Rosen P, Dart J, Reidy A, Desai P, and Sidhu M. 2001. Extracapsular cataract extraction compared with small incision surgery by phacoemulsification: a randomised trial. The British Journal of Ophthalmology 85:822-829.

Mojon-Azzi SM, and Mojon DS. 2007. Waiting times for cataract surgery in ten European countries: An analysis using data from the SHARE survey. British Journal of Ophthalmology 91:282-286.

Murthy GVS, Gupta S, Ellwein LB, Munoz SR, Bachani D, and Dada VK. 2001. A population-based eye survey of older adults in a rural district of Rajasthan: I. Central vision impairment, blindness, and cataract surgery. Ophthalmology 108:679-685.

Nirmalan PK, Thulasiraj RD, Maneksha V, Rahmathullah R, Ramakrishnan R, Padmavathi A, Munoz SR, and Ellwein LB. 2002. A population based eye survey of older adults in Tirunelveli district of south India: blindness, cataract surgery, and visual outcomes. Br J Ophthalmol 86:505-512.

Norregaard J, Hindsberger C, Alonso J, Bellan L, Bernth-Petersen P, Black C, Dunn E, Andersen TF, Espallargues M and Anderson GF. 1998. Visual outcomes of cataract surgery in the united states, canada, denmark, and spain: Report from the international cataract surgery outcomes study. Archives of Ophthalmology 116:1095-1100.

Norregaard JC. 2007. Results from the International Cataract Surgery Outcomes Study. Acta Ophthalmologica Scandinavica 85:5-32.

Pascolini D, and Mariotti SP. 2011. Global estimates of visual impairment: 2010. British Journal of Ophthalmology.

Rönbeck M, Lundström M, and Kugelberg M. 2011. Study of Possible Predictors Associated with SelfAssessed Visual Function after Cataract Surgery. Ophthalmology 118:1732-1738.

Tan JSL, Wang JJ, and Mitchell P. 2008. Influence of Diabetes and Cardiovascular Disease on the LongTerm Incidence of Cataract: The Blue Mountains Eye Study. Ophthalmic Epidemiology 15:317327.

The Royal College of Ophthalmologists. 2010. Cataract Surgery Guidelines. London, United Kingdom. Velez G, and Weiter J. 2002. Cataract extraction and age-related macular degeneration: associations, diagnosis and management. Semin Ophthalmol 17:187-195.

World Health Organisation. 1998. Informal consultation on analysis of blindness prevention outcomes. WHO/PBL/98.68 ed. Geneva: WHO.

World Health Organisation. 2006. Prevention of blindness from diabetes mellitus; report of a WHO consultation in Geneva, Switzerland. Geneva, Switzerland: World Health Organisation. 


\section{Table 1 (on next page)}

Univariate analyses of socio-demographic factors of patients based on visual outcomes after Cataract Surgery 


\begin{tabular}{|c|c|c|c|c|c|}
\hline \multirow[b]{2}{*}{ Variables } & \multicolumn{2}{|c|}{ Visual Outcome } & \multirow[b]{2}{*}{ Total } & \multirow[b]{2}{*}{$\begin{array}{c}\text { OR \& } \\
\text { 95\% CI for OR }\end{array}$} & \multirow[b]{2}{*}{ P-value } \\
\hline & $\begin{array}{l}\text { Good } \\
n=263(66 \%)\end{array}$ & $\begin{array}{l}\text { Poor } \\
n=138(34 \%)\end{array}$ & & & \\
\hline Age, years & $67.70 \pm 11.43$ & $68.82 \pm 13.28$ & $68.01 \pm 12.09$ & $1.008(0.99-1.03)$ & 0.378 \\
\hline \multicolumn{6}{|l|}{ Age group, years } \\
\hline$\leq 50$ & $20(7.6)$ & $13(9.4)$ & 33 & 1 & \\
\hline $51-80$ & $208(79.1)$ & $100(72.5)$ & 308 & $0.74(0.35-1.55)$ & 0.423 \\
\hline$>80$ & $35(13.3)$ & $25(18.1)$ & 60 & $1.10(0.46-2.61)$ & 0.831 \\
\hline \multicolumn{6}{|l|}{ Sex } \\
\hline Female & $139(52.9)$ & $62(44.9)$ & 201 & 1 & \\
\hline Male & $124(47.1)$ & $76(55.1)$ & 200 & $1.37(0.91-2.08)$ & 0.132 \\
\hline \multicolumn{6}{|l|}{ Marital Status } \\
\hline Married & $125(47.5)$ & $54(39.1)$ & 179 & 1 & 0.175 \\
\hline Unmarried & $127(48.3)$ & $80(38.6)$ & 207 & $1.46(0.95-2.23)$ & 0.082 \\
\hline Not Stated & $11(4.2)$ & $4(2.9)$ & 15 & $0.84(0.26-2.76)$ & 0.776 \\
\hline \multicolumn{6}{|l|}{ Year of First Visit to Clinic } \\
\hline $2009-2013$ & $229(87.4)$ & $109(79.0)$ & 338 & 1 & \\
\hline $2005-2008$ & $33(12.6)$ & $29(21.0)$ & 62 & $1.85(1.07-3.20)$ & $0.028 *$ \\
\hline $\begin{array}{l}\text { Time Between First Visit And } \\
\text { Operation, years }\end{array}$ & $1.55 \pm 1.48$ & $1.71 \pm 1.49$ & $1.60 \pm 1.47$ & $1.08(0.79-1.48)$ & 0.638 \\
\hline \multicolumn{6}{|l|}{$\begin{array}{l}\text { Time Between First Visit And } \\
\text { Operation, years }\end{array}$} \\
\hline$<=2$ & $188(71.5)$ & $90(71.5)$ & 278 & 1 & \\
\hline$>2$ & $75(28.5)$ & $48(34.8)$ & 123 & $1.34(0.86-2.08)$ & 0.197 \\
\hline \multicolumn{6}{|l|}{ Residence } \\
\hline ERHA areas & $165(62.7)$ & $81(58.7)$ & 246 & 1 & \\
\hline Other & $98(37.3)$ & $57(41.3)$ & 155 & $1.19(0.78-1.81)$ & 0.430 \\
\hline \multicolumn{6}{|l|}{ Occupation } \\
\hline Employed & $79(30.0)$ & $35(25.4)$ & 114 & 1 & \\
\hline $\begin{array}{r}\text { Retired } \\
\text { Unemploved/Disability }\end{array}$ & $101(38.4)$ & $63(45.7)$ & 164 & $1.41(0.85-2.34)$ & 0.186 \\
\hline Allowance & $7(2.7)$ & $8(5.8)$ & 15 & $2.58(0.87-7.67)$ & 0.088 \\
\hline Not Stated & $76(28.9)$ & $32(23.2)$ & 108 & $0.95(0.54-1.69)$ & 0.862 \\
\hline \multicolumn{6}{|l|}{ Referral Sources } \\
\hline ERHA & $90(34.2)$ & $48(34.8)$ & 138 & 1 & \\
\hline Optical & $84(31.9)$ & $41(29.7)$ & 125 & $0.92(0.55-1.53)$ & 0.734 \\
\hline Other & $69(26.2)$ & $38(27.5)$ & 107 & $1.03(0.61-1.75)$ & 0.905 \\
\hline Not Stated & $20(7.6)$ & $11(8.0)$ & 31 & $1.03(0.46-2.33)$ & 0.941 \\
\hline
\end{tabular}

$4 * p \leq 0.05 . * * p<0.001$. 


\section{Table 2 (on next page)}

Univariate analyses of clinical and surgical factors of patients Based on visual outcome after Cataract Surgery 


\begin{tabular}{|c|c|c|c|c|c|}
\hline \multirow[b]{2}{*}{ Variables } & \multicolumn{2}{|c|}{ Visual Outcome } & \multirow[b]{2}{*}{ Total } & \multirow[b]{2}{*}{$\begin{array}{c}\text { OR \& } \\
95 \% \text { CI for OR }\end{array}$} & \multirow[b]{2}{*}{ p-value } \\
\hline & $\begin{array}{c}\text { Good } \\
\mathrm{n}=263(66 \%)\end{array}$ & $\begin{array}{l}\begin{array}{l}\text { Poor } \\
n=138(34 \%)\end{array} \\
\end{array}$ & & & \\
\hline \multicolumn{6}{|l|}{ Preoperative VA } \\
\hline Poor & $122(46.4)$ & $88(63.8)$ & 210 & 1 & \\
\hline Good & $66(25.1)$ & $20(14.5)$ & 86 & $0.42(0.24-0.74)$ & $0.003 * *$ \\
\hline Borderline & $75(28.5)$ & $30(21.7)$ & 105 & $0.56(0.34-0.92)$ & $0.022 *$ \\
\hline \multicolumn{6}{|l|}{ Ocular CoMorbidity $†$} \\
\hline Absent & $195(74.1)$ & $79(57.2)$ & 274 & 1 & - \\
\hline Present & $68(25.9)$ & $59(42.8)$ & 127 & $2.14(1.39-3.31)$ & $0.001 * *$ \\
\hline \multicolumn{6}{|l|}{ Diabetes } \\
\hline Absent & $164(62.4)$ & $74(53.6)$ & 238 & 1 & - \\
\hline Present & $99(37.6)$ & $64(46.4)$ & 163 & $1.43(0.94-2.18)$ & 0.091 \\
\hline \multicolumn{6}{|l|}{ Hypertension } \\
\hline Absent & $134(51.0)$ & $85(61.6)$ & 219 & 1 & - \\
\hline Present & $129(49.0)$ & $53(38.4)$ & 182 & $0.65(0.43-0.99)$ & $0.043^{*}$ \\
\hline \multicolumn{6}{|l|}{ Cardiovascular disease } \\
\hline Absent & $236(89.7)$ & $127(92.0)$ & 363 & 1 & - \\
\hline Present & $27(10.3)$ & $11(8.0)$ & 38 & $0.76(0.36-1.58)$ & 0.457 \\
\hline \multicolumn{6}{|l|}{ High Cholesterol } \\
\hline Absent & $236(89.7)$ & $119(86.2)$ & 355 & 1 & - \\
\hline Present & $27(10.3)$ & $19(13.8)$ & 46 & $1.40(0.75-2.61)$ & 0.297 \\
\hline \multicolumn{6}{|l|}{ Intraocular Pressure } \\
\hline Normal & $238(90.8)$ & $112(81.2)$ & 350 & 1 & - \\
\hline High & $24(9.2)$ & $26(18.8)$ & 50 & $2.30(1.27-4.19)$ & $0.006^{* *}$ \\
\hline \multicolumn{6}{|l|}{ Eye Surgery Done on } \\
\hline Right & $146(55.5)$ & $73(52.9)$ & 219 & 1 & - \\
\hline Left & $117(44.5)$ & $65(47.1)$ & 182 & $1.11(0.74-1.68)$ & 0.617 \\
\hline \multicolumn{6}{|l|}{ Surgical Procedure } \\
\hline PHACO & $158(60.3)$ & $64(47.1)$ & 222 & 1 & - \\
\hline ECCE & $104(39.7)$ & $72(52.9)$ & 176 & $1.71(1.13-2.60)$ & $0.012 *$ \\
\hline \multicolumn{6}{|l|}{ Other Eye Surgeries } \\
\hline No & $249(94.7)$ & $120(87.0)$ & 369 & 1 & - \\
\hline $\mathrm{Yes}^{\wedge}$ & $14(5.3)$ & $18(13.0)$ & 32 & $2.67(1.28-5.55)$ & $0.009^{* *}$ \\
\hline
\end{tabular}

$* p \leq 0.05 .{ }^{* *} p<0.001$.

$\dagger$ includes mainly glaucoma, diabetic retinopathy, age related macular degeneration and uveitis.

$\wedge$ includes anterior vitrectomy, trabeculectomy and pterygium. 


\section{Table 3(on next page)}

Multivariate analyses of factors affecting visual outcome after Cataract Surgery. 
1

\begin{tabular}{|l|c|c|l|}
\hline Variables & Coff $(\boldsymbol{\beta})$ & OR \& 95\% CI for OR & p-value \\
\hline Hypertension & -0.52 & $0.60(0.38-0.94)$ & $0.022^{*}$ \\
Ocular Co-morbidity & 0.76 & $2.133(1.36-3.42)$ & $0.001^{* *}$ \\
Good Preoperative VA & -0.95 & $0.388(0.21-0.72)$ & $0.002^{* *}$ \\
Borderline Preoperative VA & -0.72 & $0.485(0.28-0.86)$ & $0.010^{*}$ \\
Year of First Visit & 0.81 & $2.243(1.20-4.10)$ & $0.010^{*}$ \\
Surgical Procedure & 0.45 & $1.560(1.013-2.45)$ & $0.048^{*}$ \\
Constant & -0.66 & 0.52 & $0.002^{* *}$ \\
\hline
\end{tabular}

2

3

$* p \leq 0.05 . * * p<0.001$

4 
1

Figure 1

Visual Acuity Categories before and after Cataract Surgery

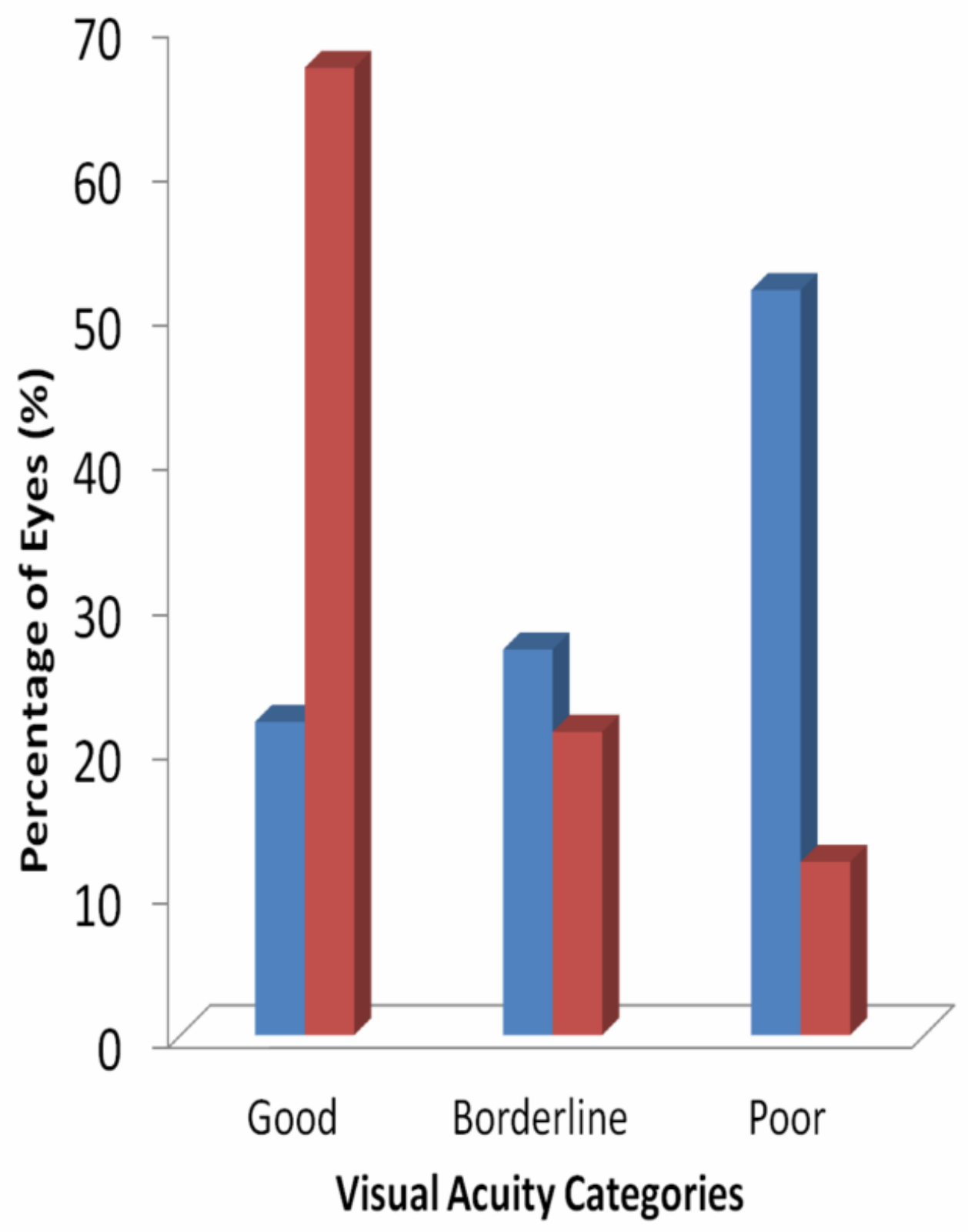

- Preoperative VA

- Post-operative VA 